\title{
Influência da resistência à compressão na molhabilidade superficial de concretos
}

\author{
Influence of concretes compressive strength \\ on superficial wettability
}

\author{
Emili Cappelari ${ }^{1}$, Caroline Giordani ${ }^{2}$, \\ Silvia Trein Heimfarth Dapper ${ }^{2}$, \\ Angela Borges Masuero ${ }^{2}$
}

\author{
${ }^{1}$ Laboratório de Materiais e Tecnologia do Ambiente Construído - LAMTAC/NORIE/EE/UFRGS. CP: 90035-190, Por- \\ to Alegre, RS, Brasil. \\ e-mail: emili_cappelari@hotmail.com \\ ${ }^{2}$ Laboratório de Materiais e Tecnologia do Ambiente Construído - LAMTAC/NORIE/PPGCI/EE/UFRGS. CP: $90035-$ \\ 190, Porto Alegre, RS, Brasil. \\ e-mail: giordani.carol@gmail.com, silviadesign@gmail.com, angela.masuero@ufrgs.br
}

\section{RESUMO}

Superfícies de concreto constituem um dos substratos nos quais o revestimento de argamassa, amplamente utilizado nas edificações, pode ser aplicado. Frequentemente, por incompatibilidade entre os substratos e a argamassa, a durabilidade do sistema de revestimento pode ser comprometida, podendo ocorrer manifestações patológicas como descolamentos e desplacamentos. Para se alcançar uma melhor adesão e aderência das argamassas de revestimento, o ideal é que se obtenha um substrato com superfície hidrofílica, resultando em uma interface com maior área de contato entre as camadas. Dentro deste contexto, o presente trabalho tem como objetivo avaliar a molhabilidade de superfícies de concreto com diferentes resistências à compressão, de forma a inferir o desempenho do ponto de vista da aderência de uma camada de revestimento de argamassa sobre estes substratos. Para isso, foram dosados cinco concretos com relações água/aglomerante variando de 0,16 à 0,57 . A caracterização do concreto quanto à resistência à compressão foi realizada de acordo com a ABNT NBR 5739:2007, e a absorção de água por capilaridade conforme a ABNT NBR 9779:2012. O molhamento superficial dos concretos foi avaliado através de um equipamento de captura do perfil de gota séssil. Verificou-se que a resistência à compressão do concreto possui uma influência na molhabilidade de sua superfície. Concretos com maiores resistência à compressão possuem, além de uma menor absorção, como esperado, uma menor molhabilidade. A aplicação da argamassa sobre um substrato de concreto com maior resistência à compressão e baixa porosidade capilar pode resultar em uma menor absorção da pasta da argamassa pelos poros do substrato e uma menor extensão de contato, dificultando o desenvolvimento do intertravamento mecânico e a aderência entre os materiais.

Palavras-chave: Molhabilidade. Superfície hidrofílica. Superfície de Concreto. Revestimento de argamassa.

\section{ABSTRACT}

Concrete surfaces are one of the substrates on which the mortar coating, widely used in buildings, can be applied. Frequently, when there are incompatibilities between the substrate and the mortar, the coating system's durability can be compromised, causing pathological manifestations such as detachments and displacements. To reach a better mortar coating adhesion and adherence, would be ideal that the substrate presents a hydrophilic surface, which allows a greater coating spreading. In this context, the present research aims to evaluate the superficial wettability of concretes with different compressive strength, in order to infer the performance from the point of view of adherence of a mortar coating layer on these substrates. Five concretes were dosed with different proportions and water/binder ratios, resulting in different values of compressive strength at 28 days. Concrete characterization in terms of compressive strength was done according to ABNT NBR 5739:2007, and water absorption by capillarity according to ABNT NBR 9779:2012. The concretes surface wetness test was evaluated through a sessile drop profile capture equipment. It was identified that the concretes compressive strenght has an influence on the wettability of its surfaces. Concretes with 
higher compressive strength have, beyond a lower absorption, a lower wettability. The mortar coating applied on a concrete substrate with higher compressive strength and lower capillary porosity can result in a lower mortar paste absorption by substrate pores and a lower contact extension, hampering the development of the mechanical interlocking and the adherence between the materials.

Keywords: Wettability. Hydrophilic surface. Concrete surface. Mortar coating.

\section{INTRODUÇÃO}

Buscando reduzir a utilização de espaço físico, as construções têm exigido estruturas cada vez mais esbeltas. Por possuírem seções menores, o concreto deve apresentar maior resistência à compressão, vindo a apresentar também, de forma geral, uma menor absorção. Estas características são benéficas do ponto de vista de durabilidade, principalmente no caso de estruturas de concreto aparente. Porém, as características do substrato podem influenciar negativamente no espalhamento e consequente adesão da argamassa, no caso de concretos revestidos com este material, resultando em revestimentos que não cumprem suas funções e que, por vezes, não asseguram o desempenho adequado da edificação. O estudo dos fenômenos das estruturas de concreto que interferem na adesão dos materiais de revestimento implica no conhecimento acerca das características da superfície deste substrato, especificamente neste caso, o concreto.

A adesão de argamassas de revestimento ocorre no momento em que a argamassa no estado fresco é lançada sobre o substrato poroso, e a aderência se desenvolve ao longo do processo de hidratação dos aglomerantes da argamassa, ou seja, de cura da argamassa [1]. A qualidade da adesão indicará a aderência do revestimento que, segundo a ABNT NBR 13528 [2, p. 1], entende-se como a "propriedade do revestimento de resistir às tensões atuantes na interface do substrato.”.

A permeabilidade indica a facilidade com que um fluído consegue passar através da estrutura interna de um determinado corpo. No concreto, a conectividade entre os poros torna-o permeável [3]. A porosidade e a interconexão entre os canais capilares, juntamente com a absorção, é um parâmetro importante para a aderência das argamassas de revestimento.

Contudo, há uma relação inversa entre a porosidade e a resistência dos sólidos [4]. A quantidade de água adicionada à mistura e o grau de hidratação do cimento influenciam a quantidade de vazios capilares. Assim, o aumento do grau de hidratação do cimento e a redução da relação água/cimento pode aumentar a resistência à compressão e diminuir a porosidade capilar. Consequentemente, essas características podem dificultar a ocorrência da aderência do revestimento de argamassa e do intertravamento mecânico, por causa da baixa absorção da pasta pelos poros do substrato.

Dessa forma, o presente trabalho teve como objetivo analisar a relação existente entre a resistência à compressão de concretos com diferentes traços e relações água/aglomerante, com a molhabilidade e a absorção de água por capilaridade destes materiais.

Essa investigação torna-se pertinente, pois a absorção capilar ocorre imediatamente após o primeiro contato do fluído com a superfície do substrato [5], o que indica uma possível influência da molhabilidade do substrato na adesão e aderência das argamassas de revestimento. O fenômeno de molhabilidade de uma superfície pode ser entendido como a tendência de um determinado fluido espalhar ou aderir sobre uma superfície sólida. A molhabilidade pode ser quantificada por meio da medição do ângulo de contato formado por uma gota de água aplicada na superfície. As interações entre a argamassa e o substrato devem ter os menores ângulos de contato possíveis, bem como elevadas pressões capilares, ou seja, o ideal é que se obtenha um substrato com superfície hidrofílica, com boa molhabilidade, para se alcançar uma maior adesão dos revestimentos de argamassa [6].

\subsection{Teoria da molhabilidade}

A molhabilidade é, essencialmente, determinada por dois fatores: a estrutura química da superfície e a rugosidade da mesma. Segundo a teoria de WENZEL [7], o líquido entra em contato com toda a superfície, preenchendo todas as cavidades existentes. Portanto, a rugosidade é um parâmetro capaz de induzir tanto o carácter hidrofílico como hidrofóbico numa superfície. De acordo com o modelo de CASSIE-BAXTER [8], o líquido não molha completamente a superfície rugosa, devido à existência de ar entre as depressões, e a pequena área de contato entre a gota e a superfície sólida permite que esta role facilmente sobre a superfície.

Idealmente, a forma de uma gota é determinada pela tensão superficial do líquido. Em um líquido puro, cada molécula é puxada com igual força em todas as direções pelas moléculas vizinhas, resultando numa força líquida igual a zero. No entanto, nas moléculas expostas à superfície não há equilíbrio de forças, pois não existem moléculas vizinhas em todas as direções. Assim, essas moléculas são puxadas para o interior 
pelas moléculas próximas, conforme a Figura 1, originando uma pressão interna. Por esse motivo, o líquido contrai a sua área superficial para manter a menor energia livre na superfície, segundo LATTHE et al.[9] e SNOEIJER $^{1}$ et al. apud VIECHINESKI [10].

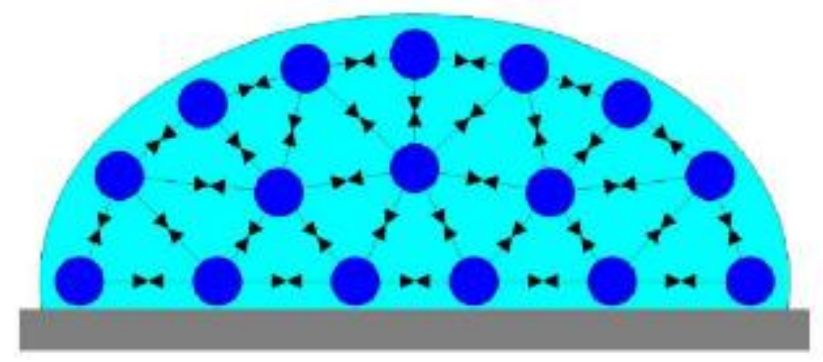

Figura 1: Tensão superficial em um líquido. Fonte: adaptada de VERPLANK ${ }^{2}$ et al.apud VIECHINESKI [10].

Segundo NUNES [11], quando uma gota de líquido é colocada sobre uma superfície sólida, forma-se uma interface tripla entre o sólido, o líquido e o vapor, cuja posição de equilíbrio depende das forças associadas às tensões interfaciais. A Figura 2 ilustra uma gota de líquido (L) sobre uma superfície sólida (S), com o vapor $(\mathrm{V})$ como terceira fase. $\mathrm{O}$ ângulo $\theta$, definido entre a superfície sólida e a tangente à superfície do líquido, num ponto da linha de contato com o sólido, é considerado o ângulo de contato.

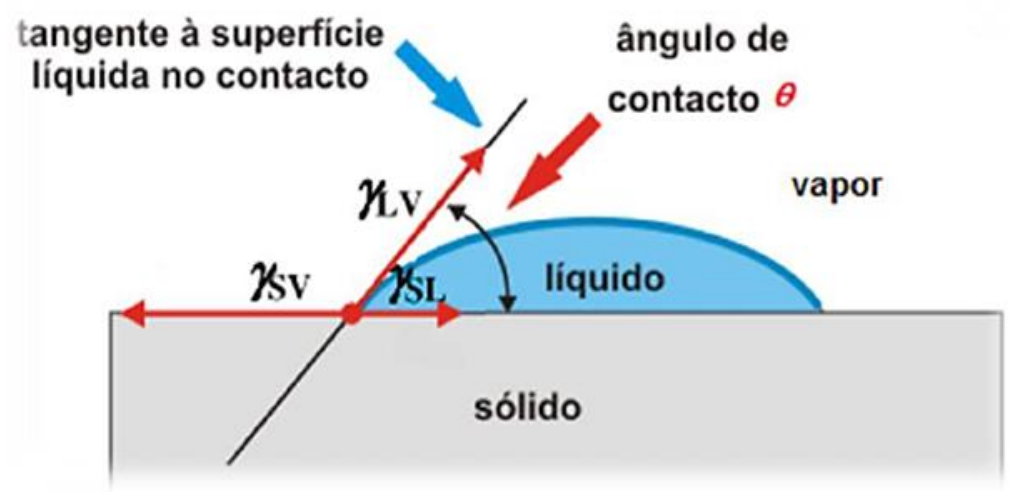

Figura 2: Ângulo de contato de equilíbrio entre um líquido e uma superfície sólida. Fonte: NUNES [11].

COURARD et al. [12, p. 30, tradução nossa] indicam que, "Com o aumento do ângulo de contato, ocorrerá um menor molhamento da superfície.”. KINDLEIN JUNIOR et al. [13] classificam as superfícies de acordo com esta característica. Quando um material confere a uma gota um baixo ângulo de contato, ou seja, um ângulo inferior a $90^{\circ}$, ele é considerado hidrofílico. Quando este ângulo se apresenta próximo ou igual a $0^{\circ}$, o material é considerado superhidrofílico. Por outro lado, é considerado hidrofóbico um material que apresente um ângulo de contato maior que $100^{\circ}$, e superhidrofóbico quando esse valor excede os $150^{\circ}$. A Figura 3 apresenta imagens esquemáticas de possíveis ângulos de contato de gotas de água quando depositadas sobre superfícies de sólidos diferentes [14].

\footnotetext{
${ }^{1}$ SNOEIJER, J. H.; ANDREOTTI, B. A microscopic view on contact angle selection. Physics of Fluids, v. 20, n. 5, p. 057101.1-057101.11, 2008.

${ }^{2}$ VERPLANCK, N. et al. Wettability switching techniques on superhydrophobic surfaces. Nanoescale Research Letters, v.2, n.12, p.577-596, 2007.
} 


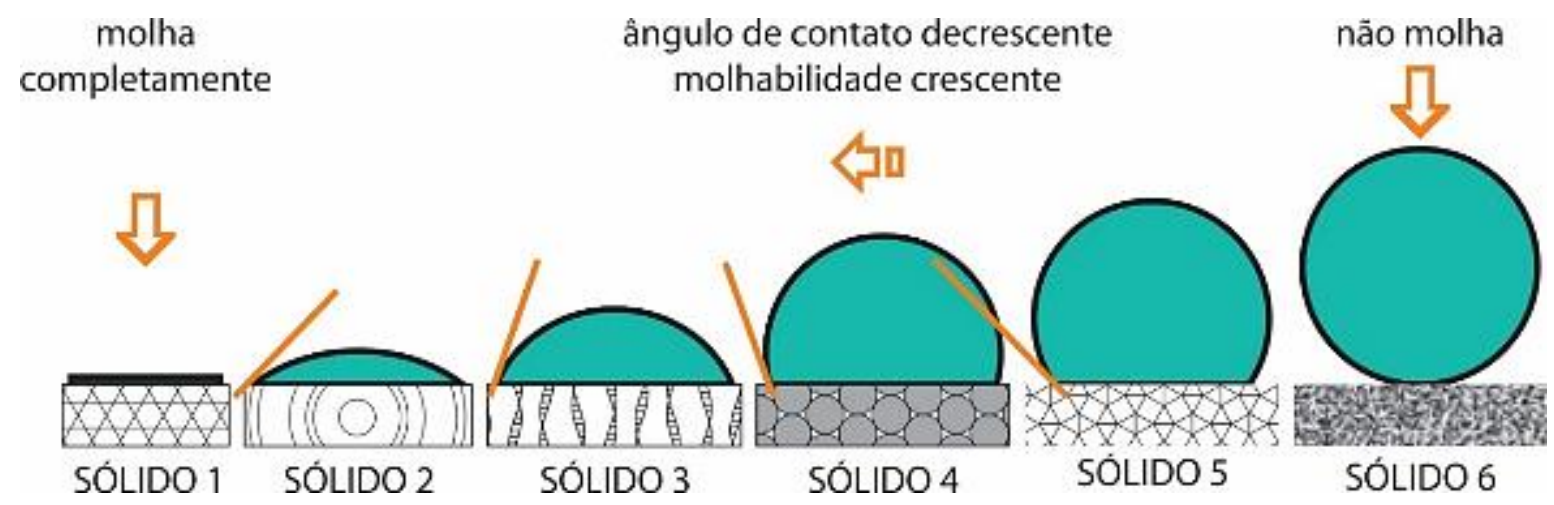

Figura 3: Esquema de diferentes ângulos de contato de uma gota d'água quando depositada sobre diferentes superfícies de sólidos. Fonte: DAPPER [14].)

Conforme apresentado por STOLZ e MASUERO [15], quanto menor for a capacidade de molhabilidade do substrato, maior será a porcentagem de falhas na interface substrato-argamassa devido à hidrofobicidade da superfície, que impede o espalhamento da argamassa. Sendo assim, o conhecimento do comportamento dessas superfícies é fundamental para o controle das propriedades mecânicas e de durabilidade dos materiais que compõem o sistema da envoltória das edificações. O desempenho deste e outros sistemas ganhou importância e evidência principalmente com a publicação da ABNT NBR 15575-1 [16] em 2013. Este documento estabelece que o nível de desempenho do sistema de vedação externa deve ser garantido por durante uma vida útil de projeto mínima de 40 anos e, no caso da vedação interna, por durante 20 anos.

\subsection{Absorção de água por capilaridade}

A absorção por capilaridade ou sucção capilar ocorre nos poros capilares da superfície do concreto quando submetido ao molhamento, por condutividade hidráulica, em que o fluxo de água entre o substrato e o revestimento ocorre em função da diferença de pressão capilar, até o equilíbrio dos poros [17].

A ABNT NBR 9779[18] prescreve o método para determinação da absorção de água, através de ascensão capilar, de argamassas e concretos endurecidos. Nos concretos, os poros são formados por diversos motivos, sendo alguns destes devido aos produtos de hidratação do cimento, ar aprisionado durante o processo de lançamento do concreto na fôrma, pela evaporação da água sobressalente do concreto, retração por secagem, expansão térmica, cura inadequada, entre outros [19]. A superfície do concreto, que se encontra na interface concreto-fôrma, é uma zona com espessura de alguns milímetros, muito rica em pasta cimentícia e que, normalmente, apresenta maior porosidade do que o restante do substrato, sendo mais suscetível à troca de fluídos [20].

Segundo CARASEK [21], tanto os poros do substrato quanto da argamassa fresca podem ser representados como tubos cilíndricos independentes. Porém, a autora comenta que, no substrato, os poros apresentam-se inicialmente vazios e com raios constantes ao longo do tempo; e, na argamassa fresca, os poros estão saturados e os raios variam em função do tempo, visto que suas dimensões são reduzidas ao longo do processo de hidratação dos aglomerantes. Sendo assim, o transporte de água entre os poros da matriz e do substrato pode ser explicado pela teoria dos poros ativos. Esta teoria relaciona a capilaridade e a consequente capacidade de absorção dos substratos e a capacidade de retenção de água da argamassa matriz. De acordo com SCARTEZINI [22], "Os poros ativos são aqueles que possuem força capilar suficiente para exercer a ação de suç̧ão de água.”.

Segundo GALLEGOS ${ }^{3}$ apud SCARTEZINI [22], poros inferiores a $0,1 \mu \mathrm{m}$ não são considerados como poros ativos, pois absorvem quantidades insignificantes de água, apesar de sua força capilar elevada; e poros maiores que $5 \mu \mathrm{m}$ também são inoperantes, porque não possuem força capilar suficiente para vencer os poros existentes na argamassa. Conforme GROOT ${ }^{4}$ apud SCARTEZINI [22], imediatamente após o contato entre a

\footnotetext{
${ }^{3}$ GALLEGOS, h. Adhesipon entre morteiro y las unidades de albañilería. In: SIMPÓSIO BRASILEIRO DE TECNOLOGIA DAS ARGAMASSAS, $1^{\circ}$, Goiânia, 16 a 18 de agosto de 1995. Anais. Goiânia. UFG/ANTAC, 1995, P.177-133.

${ }^{4}$ GROOT, C.J.W.P. Effects of water on mortar - brick bond. Techniche University Delft, 1993.
} 
argamassa e a base absorvente, a água começa a fluir da argamassa em direção à base. Esse fluxo permanece até que o equilíbrio seja alcançado entre sucção capilar e as forças físico-químicas de retenção de água, fazendo com que o aperto mecânico das partículas no interior da argamassa seja tal que o raio médio dos seus capilares se torne igual aos capilares da base, interrompendo-se com isto o fluxo de água por sucção.

Com a densificação das partículas no interior da argamassa, o raio dos capilares diminui, concorrendo com os poros do substrato em termos de força capilar. No momento em que os poros da argamassa se tornam menores que os existentes no substrato, esses poros passam a ser chamados poros ativos, pois possuem força capilar suficiente para retirar água do substrato em direção à argamassa. Nesse momento ocorre a reversão do sentido de sucção de água, ocorrendo da base para a matriz, conforme figura 4 [22].
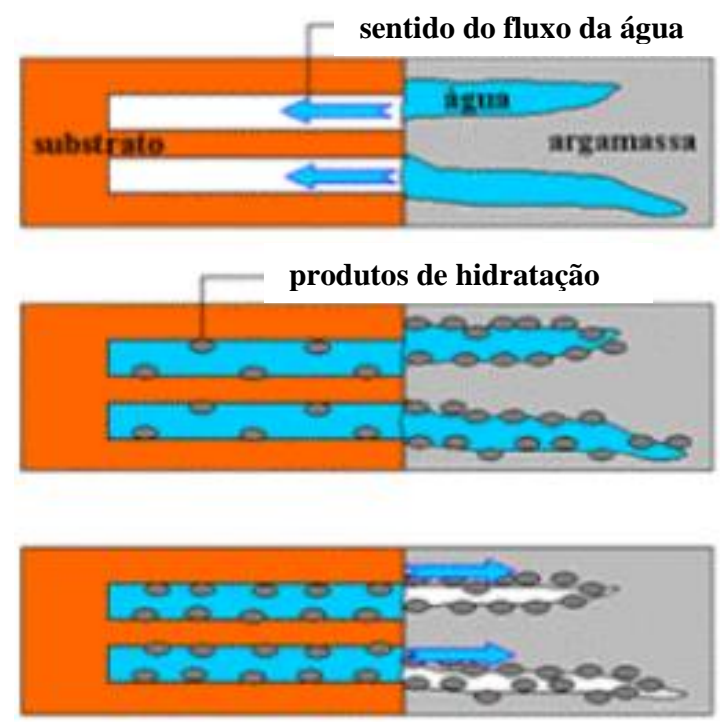

Poros do substrato, inicialmente secos, absorvem água da argamassa fresca.

A absorção de água é acompanhada pela precipitação de produtos de hidratação do cimento no interior dos poros e um aperto das partículas próximas à região de interfaces.

Poros no interior da argamassa exercem maior pressão capilar do que os poros do substrato, invertendo o sentido do fluxo de água.

Figura 4: Representação esquemática do fluxo de água reversível, após a formação de poros ativos no interior da argamassa de revestimento. Fonte: SCARTEZINI [22].

\section{PROGRAMA EXPERIMENTAL/MATERIAIS E MÉTODOS}

Para atingir os objetivos desta pesquisa, foram propostos concretos que resultassem em valores distintos de resistência à compressão aos 28 dias. Os diferentes traços e relações água/aglomerante foram adaptados do trabalho de ROHDEN [23].

Os aglomerantes usados foram cimento Portland CPV-ARI e sílica ativa; como agregado miúdo, areia quartzosa do Rio Jacuí; e, como agregado graúdo, brita basáltica. Os agregados graúdos e miúdos do concreto foram caracterizados, sendo que o agregado graúdo apresentou um módulo de finura de 7,11, dimensões variando entre 9,5 a $25 \mathrm{~mm}$, massa específica de $2,98 \mathrm{~g} / \mathrm{cm}^{3}$ e massa unitária de $1,38 \mathrm{~g} / \mathrm{cm}^{3}$; e o agregado miúdo apresentou módulo de finura de 2,26, diâmetro máximo de 2,4mm, massa específica de 2,64g/ $\mathrm{cm}^{3}$, massa unitária de $1,5 \mathrm{~g} / \mathrm{cm}^{3}$ e absorção de água de $1,05 \%$. Foi utilizada água proveniente da rede de abastecimento local (DMAE - Porto Alegre) e aditivo superplastificante sintético de alto desempenho à base de polímeros policarboxilatos, líquido, de densidade $1,12 \mathrm{~g} / \mathrm{cm}^{3}$, este último com o intuito de ajustar o abatimento, definido para ser maior do que $100 \mathrm{~mm}$.

Na tabela 1 são apresentados os dados dos diferentes concretos. O traço apresenta a relação, em massa, entre cimento CPV:sílica ativa:areia:brita. O teor de aditivo foi calculado relacionando-se a quantidade de aditivo utilizado à massa de cimento.

Tabela 1: Traço e relação água/aglomerante dos diferentes concretos (cimento CP V:sílica ativa:areia quartzosa:brita basáltica), em massa.

\begin{tabular}{l|l|l|l|l|l|l}
\hline TRAÇO & $\begin{array}{l}\text { RELAÇÃo ÁGUA/ } \\
\text { AGLOMERANTE }\end{array}$ & $\begin{array}{l}\text { TRAÇO EM } \\
\text { MASSA }\end{array}$ & $\begin{array}{l}\text { TEOR DE } \\
\text { ARGAMASSA } \\
(\%)\end{array}$ & $\begin{array}{l}\text { TEOR DE } \\
\text { ADITIVO } \\
(\%)\end{array}$ & $\begin{array}{l}\text { ABATIMENTO } \\
(\text { MM) }\end{array}$ & $\begin{array}{l}\text { CLASSE DE } \\
\text { ABATIMENTO } \\
\text { [24] }\end{array}$ \\
\hline 1 & 0,16 & $1: 0,08: 0,96: 1,96$ & 51 & 2,27 & 100 & S100 \\
\hline
\end{tabular}




\begin{tabular}{l|l|l|l|l|l|l}
\hline 2 & 0,19 & $1: 0,08: 1,03: 2,03$ & 51 & 2,58 & 155 & $\mathrm{~S} 100$ \\
\hline 3 & 0,24 & $1: 0,08: 1,20: 2,17$ & 51 & 1,06 & 140 & $\mathrm{~S} 100$ \\
\hline 4 & 0,35 & $1: 0,08: 1,54: 2,45$ & 52 & 0,48 & 170 & $\mathrm{~S} 160$ \\
\hline 5 & 0,57 & $1: 0,08: 2,26: 3,05$ & 52 & - & 165 & $\mathrm{~S} 160$ \\
\hline
\end{tabular}

Para cada traço, foram moldados 6 corpos de prova cilíndricos $10 \times 20 \mathrm{~cm}$, em fôrmas de aço previamente tratadas com desmoldante à base de óleo mineral, e 3 corpos-de-prova prismáticos de 10x10x5cm, em fôrmas de compensado naval, estas sem desmoldante, uma vez que a superfície em contato com a fôrma foi utilizada para a medição do ângulo de contato. Os corpos de prova foram preenchidos em duas etapas, e submetidos a adensamento em mesa vibratória por 15 e 30 segundos, respectivamente. Após desmoldagem, as amostras foram submetidas à cura em ambiente com temperatura e umidade controlados durante 28 dias até o início dos ensaios.

Três dos corpos de prova cilíndricos foram caracterizados quanto à resistência à compressão, aos 28 dias de idade, segundo a NBR 5739 [25], utilizando-se máquina de ensaio EMIC, com limite de carga de $2000 \mathrm{kN}$. Antes do procedimento, os corpos de prova tiveram suas bases aplainadas em retífica diamantada de eixo vertical e, após, foram medidos e pesados para cálculo da densidade de massa do concreto no estado endurecido úmido.

Para o ensaio de absorção de água por capilaridade adaptado [26, 27, 28], foram utilizadas as 3 amostras cilíndricas restantes. Aos 27 dias, estas foram secas em estufa a $105^{\circ} \mathrm{C}$, até ser verificada a constância de massa. Este dado foi relacionado com o volume do corpo de prova, resultando na densidade de massa do concreto no estado endurecido seco. Retiradas as amostras da estufa, aos 28 dias, esperava-se esfriarem para serem impermeabilizadas lateralmente com emulsão acrílica, em duas demãos cruzadas, com intervalo de 30 a 60 minutos entre cada demão, de forma a impedir a absorção ou evaporação de água pelas laterais do corpo de prova. Após cura do produto, aos 29 dias, as amostras foram submetidas ao ensaio de acordo com a NBR $9779[18]$.

A molhabilidade das superfícies dos concretos foi avaliada com os corpos de prova prismáticos, na face em contato com a fôrma de compensado naval, aos 31 dias. Foi realizada por meio de um equipamento de medição de gota séssil, da marca Pixelink, o qual captura a imagem do perfil de uma gota d'água quando depositada sobre a superfície sólida utilizando-se uma seringa, possibilitando a medição do ângulo de contato através de um software gráfico. Em cada amostra, foram depositadas 3 gotas de água.

\section{RESULTADOS E DISCUSSÕES}

A seguir são apresentados os resultados dos ensaios realizados no estado endurecido para a caracterização dos concretos. A análise estatística dos resultados (ANOVA - análise de variância) foi realizada considerando-se um intervalo de confiança de $95 \%$. O traço de concreto exerceu influência significativa sobre todas as variáveis de resposta analisadas neste trabalho (resistência à compressão, absorção de água por capilaridade, ângulo de contato e densidade de massa no estado endurecido), conforme apresentado na Tabela 2.

Tabela 2: ANOVA indicando que o traço de concreto exerce influência significativa sobre todas variáveis de resposta deste trabalho: resistência à compressão, densidade de massa no estado endurecido úmido e seco, absorção de água por capilaridade e ângulo de contato.

\begin{tabular}{l|l|l|l|l|l|l|l}
\hline $\begin{array}{l}\text { VARIÁVEL DE } \\
\text { RESPOSTA }\end{array}$ & FATOR CONTROLÁVEL & SQ & GL & MQ & F & P & SIGNIFICATIVO \\
\hline $\begin{array}{l}\text { Resistência à com- } \\
\text { pressão }\end{array}$ & Traço do concreto & 6797,1 & 4 & 1699,3 & 20,810 & 0,000078 & Sim \\
\cline { 2 - 8 } & Erro & 816,6 & 10 & 81,7 & & & \\
\hline $\begin{array}{l}\text { Densidade de mas- } \\
\text { sa no estado endu- } \\
\text { recido úmido }\end{array}$ & Traço do concreto & 32238,0 & 4 & 8060,0 & 40,400 & 0,000004 & Sim \\
\cline { 2 - 9 } & Erro & 1996,0 & 10 & 200,0 & & & \\
$\begin{array}{l}\text { Densidade de mas- } \\
\text { sa no estado endu- } \\
\text { recido seco }\end{array}$ & Traço do concreto & 74354,0 & 4 & 18589,0 & 38,500 & 0,000005 & Sim \\
\hline & Erro & 4831,0 & 10 & 483,0 & & & \\
\hline \begin{tabular}{l} 
Absorção de água \\
\hline
\end{tabular} & Traço do concreto & 1,5 & 4 & 0,4 & 1035,252 & 0,000000 & Sim \\
\hline
\end{tabular}




\begin{tabular}{l|l|l|l|l|l|l|l}
\hline \multirow{2}{*}{ por capilaridade } & Tempo $(\mathrm{h})$ & 0,7 & 4 & 0,2 & 445,315 & 0,000000 & Sim \\
\cline { 2 - 8 } & $\begin{array}{l}\text { Traço do concre- } \\
\text { to*Tempo }(\mathrm{h})\end{array}$ & 0,5 & 16 & 0,0 & 79,346 & 0,000000 & Sim \\
\cline { 2 - 8 } & Erro & 0,0 & 50 & 0,0 & & & \\
\hline $\begin{array}{l}\text { Absorção de água } \\
\text { por capilaridade - } \\
\text { 72h }\end{array}$ & Traço do concreto & 1,0 & 4 & 0,2 & 288,139 & 0,000000 & Sim \\
\cline { 2 - 8 } & Erro & 0,0 & 10 & 0,0 & & & \\
\hline $\begin{array}{l}\text { Altura de Absorção } \\
\text { de água por capila- } \\
\text { ridade - 72h }\end{array}$ & Traço do concreto & 31741,4 & 4 & 7935,4 & 228,189 & 0,000000 & Sim \\
\hline \multirow{2}{*}{\begin{tabular}{l} 
Angulo de contato \\
\cline { 2 - 8 }
\end{tabular}} & Erro & 2260,4 & 65 & 34,8 & & & \\
\hline
\end{tabular}

\subsection{Resistência à compressão}

Os resultados obtidos no ensaio de resistência à compressão dos concretos se encontram na Tabela 3 e estão representados na Figura 5.

Tabela 3: Resistência à compressão média, desvio padrão e variação para cada um dos traços de concreto moldados, aos 28 dias.

\begin{tabular}{l|l|l|l}
\hline TRAÇO & RESISTÊNCIA MÉDIA (MPA) & DESVIO PADRÃO (MPA) & $\begin{array}{l}\text { DESVIO PADRÃO / } \\
\text { RESISTÊNCIA MÉDIA (\%) }\end{array}$ \\
\hline 1 & 103,22 & 13,77 & 13 \\
\hline 2 & 105,98 & 3,48 & 3 \\
\hline 3 & 87,91 & 13,11 & 15 \\
\hline 4 & 85,42 & 5,55 & 6 \\
\hline 5 & 46,42 & 1,84 & 4 \\
\hline
\end{tabular}

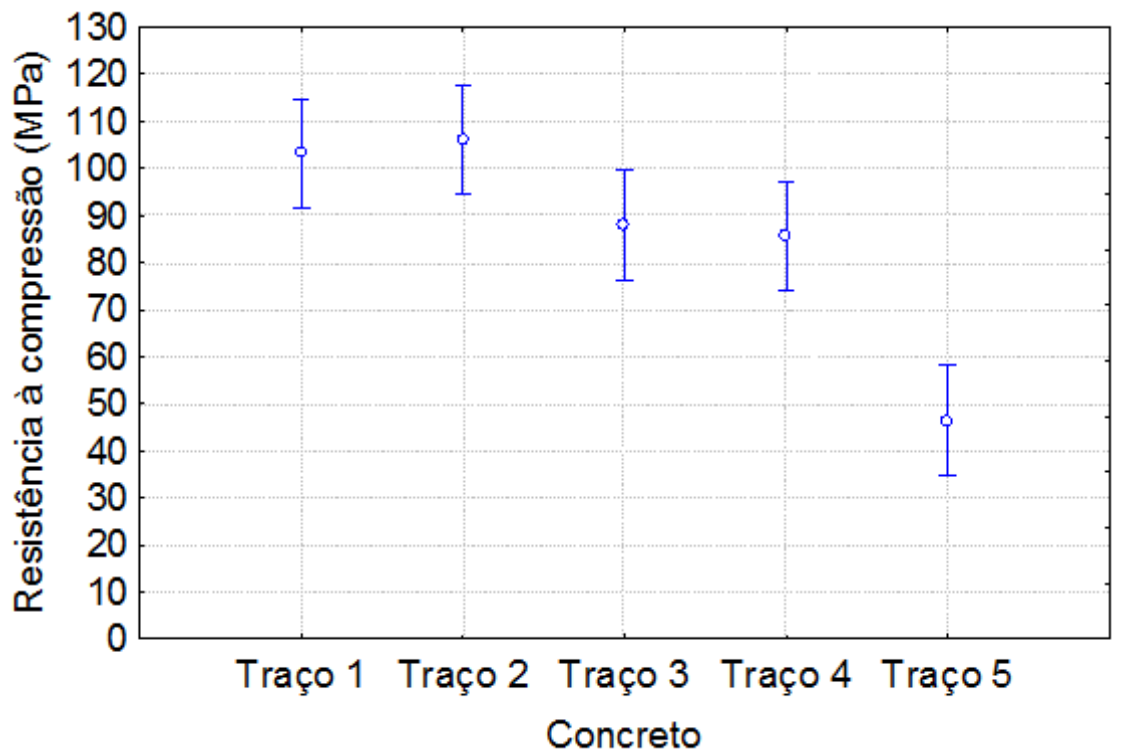

Figura 5: Resistência à compressão em função do traço dos concretos moldados, LS means. 
Foi verificado, com o teste comparativo de médias de Duncan (Tabela 4), que o traço 1 apresenta resistência à compressão significativamente semelhante ao traço 2 e 3 (embora estes dois últimos não possuam resistências consideradas semelhantes entre si), e o traço 3 não apresenta diferença estatística com relação ao traço 4 quanto a este fator. Estes resultados podem estar relacionados com a variabilidade apresentada pelos traços 1 e 3, o que se deve também a sua elevada resistência à compressão.

Tabela 4: Análise de Duncan entre a resistência à compressão dos diferentes traços de concreto; há diferença significativa entre dois traços comparados quanto ao fator analisado quando o valor é menor de 0,05 .

\begin{tabular}{l|l|l|l|l|l}
\hline & TRAÇO 1 & TRAÇO 2 & TRAÇO 3 & TRAÇO 4 & TRAÇO 5 \\
\hline TRAÇO 1 & & 0,716138 & 0,064849 & 0,045557 & 0,000086 \\
\hline TRAÇO 2 & 0,716138 & & 0,041059 & 0,027509 & 0,000057 \\
\hline TRAÇO 3 & 0,064849 & 0,041059 & & 0,762478 & 0,000371 \\
\hline TRAÇO 4 & 0,045557 & 0,027509 & 0,762478 & & 0,000494 \\
\hline TRAÇO 5 & 0,000086 & 0,000057 & 0,000371 & 0,000494 & \\
\hline
\end{tabular}

De acordo com a tabela 3, a maior resistência média foi apresentada pelo traço 2. Este resultado não apresentou-se conforme o esperado, uma vez que, menores resistências são esperadas em concretos com maior relação água/aglomerante. Desta forma, foi proposto relacionar cada traço com sua resistência potencial (Figura 6), sendo esta definida como a maior resistência obtida dentre os três corpos-de-prova. Observa-se, portanto, a relação decrescente entre a resistência à compressão potencial e o traço do concreto.

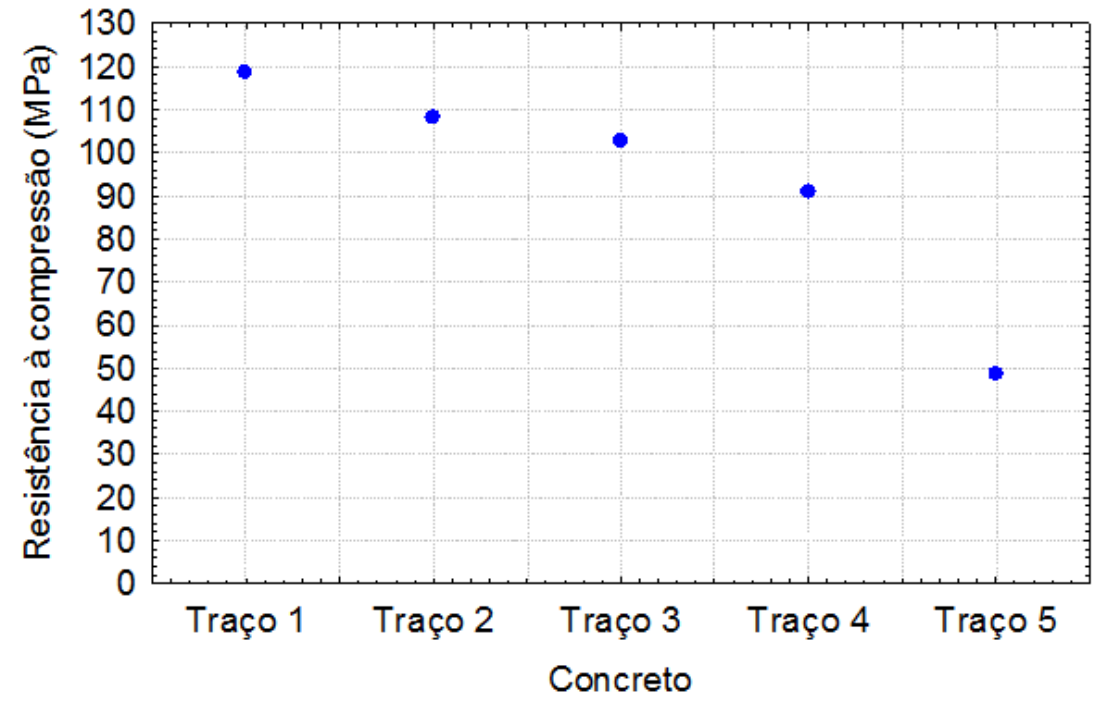

Figura 6: Resistência à compressão potencial em função do traço dos concretos moldados.

\subsection{Absorção de água por capilaridade}

Os resultados de absorção de água por capilaridade durante 3h, 6h, 24h, 48h e 72h, para cada um dos traços, estão apresentados na figura 7. 


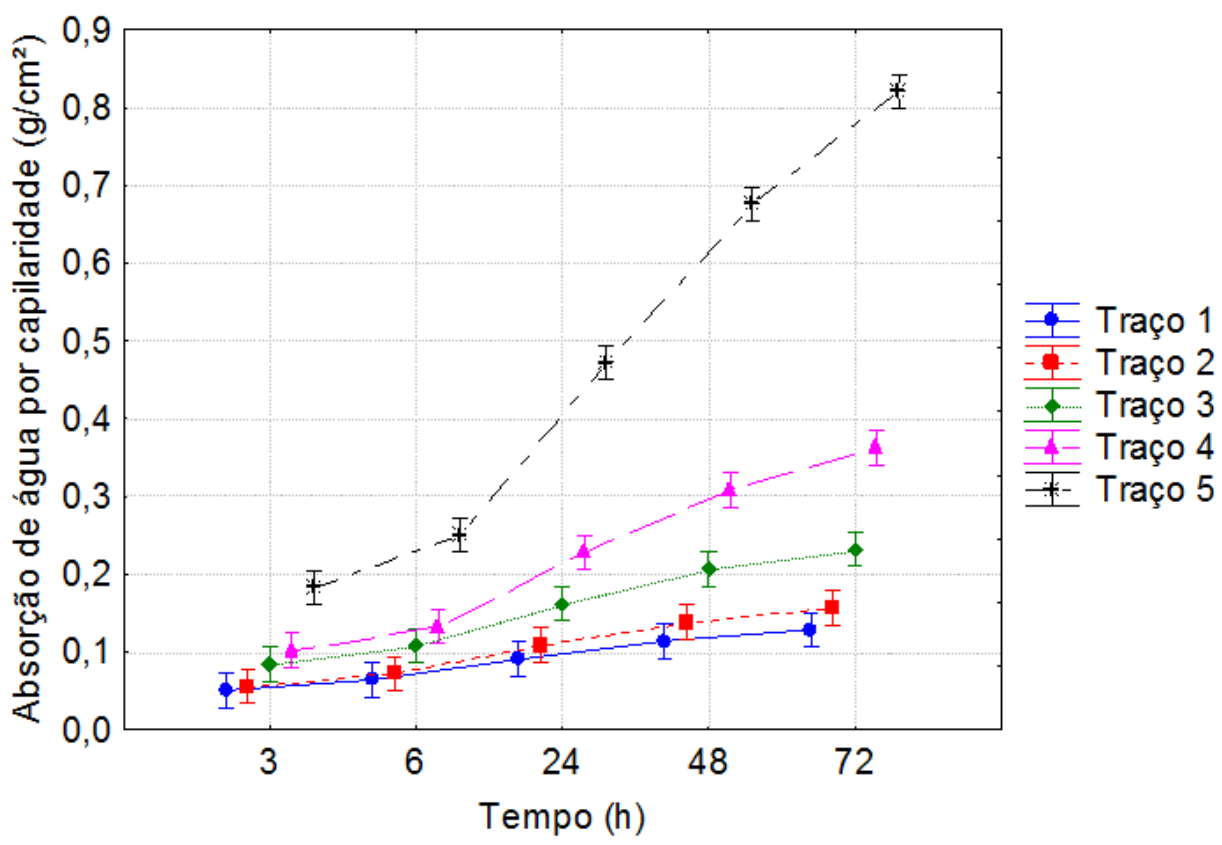

Figura 7: Absorção de água por capilaridade dos concretos com diferentes traços, em função do tempo, LS means.

Na Figura 7, percebe-se que a absorção de água por capilaridade média do traço 1 cresceu suavemente com o passar do tempo, atingindo aproximadamente $0,3 \mathrm{~g} / \mathrm{cm}^{2}$. Por sua vez, o traço 5 apresentou um relevante aumento da absorção ao longo do tempo, e em 72 horas, apresentou uma absorção de água por capilaridade média próxima a $0,9 \mathrm{~g} / \mathrm{cm}^{2}$. Esse resultado mostra-se coerente, pois o traço 1, por possuir menor relação água/aglomerante, pode apresentar menos poros do que o traço 5, e desta forma, absorve uma menor quantidade de água em um mesmo intervalo de tempo. Os demais traços apresentaram comportamentos intermediários a estes dois extremos.

Também é importante destacar, a partir da Figura 8, que o comportamento inicial da absorção por capilaridade permaneceu ao longo do tempo, demonstrando que a absorção inicial foi determinante para a absorção total do concreto.

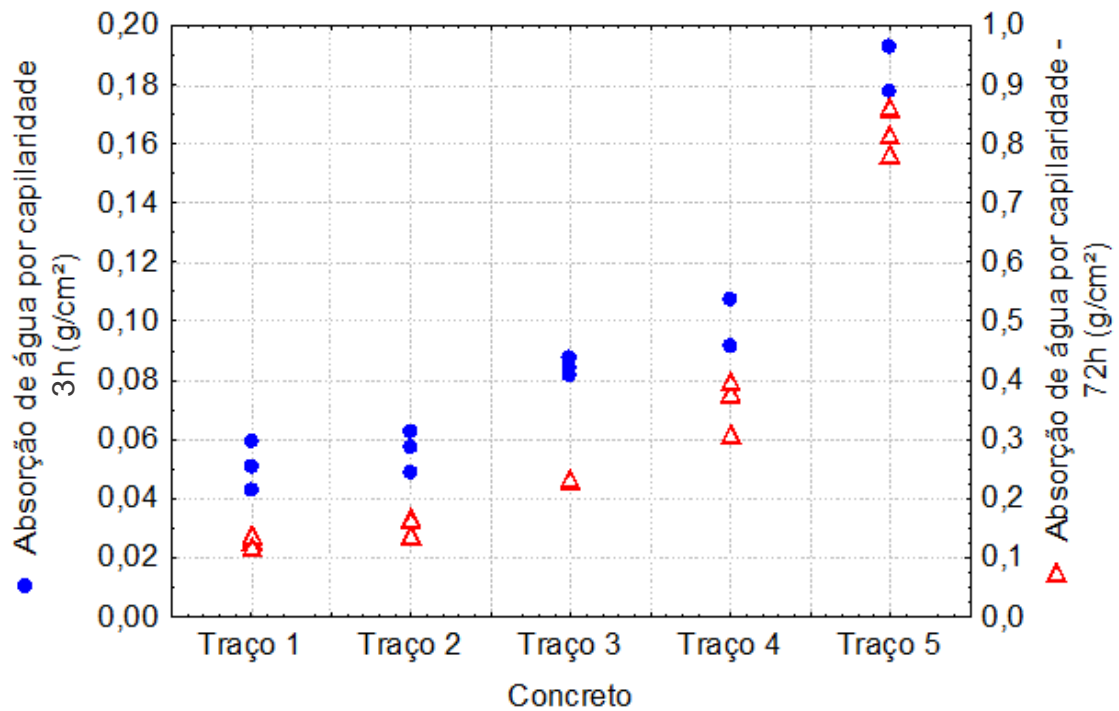

Figura 8: Absorção de água por capilaridade dos concretos com diferentes traços, após 3 e 72 horas de ensaio.

Corroborando com os fatos descritos anteriormente, a figura 9 apresenta a altura da absorção de água por capilaridade após 72 horas de ensaio, para cada um dos traços moldados. O aumento desta altura indica uma maior absorção de água por capilaridade, e também se apresenta em função do aumento da relação 
água/aglomerante dos concretos.

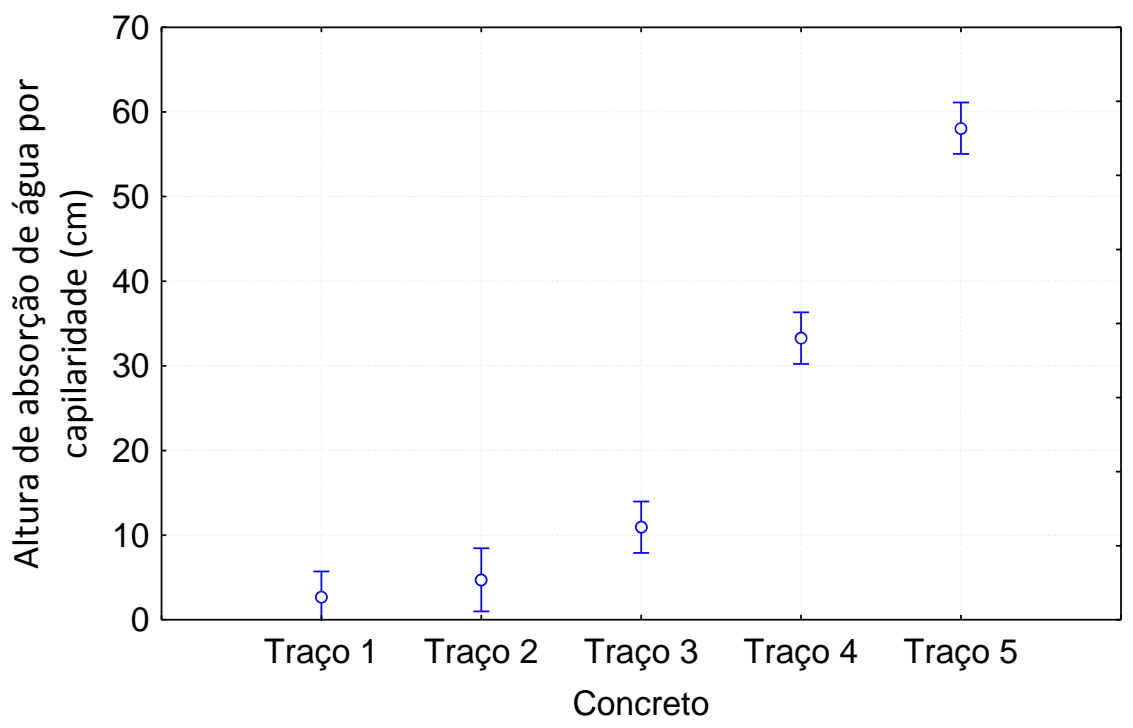

Figura 9: Altura de absorção de água por capilaridade dos concretos com diferentes traços, após 72 horas de ensaio, LS means.

\subsection{Densidade de Massa no Estado Endurecido}

A densidade de massa no estado endurecido, tanto realizada com os corpos de prova úmidos, quanto secos, apresentaram comportamentos semelhantes (Figura 10). Quanto menor a quantidade de aglomerantes e maior a relação água/aglomerante, menor a densidade de massa do concreto, provavelmente, devido a presença de maior quantidade de poros. Verifica-se, ainda, a menor densidade de massa dos concretos no estado seco do que quando no estado úmido.

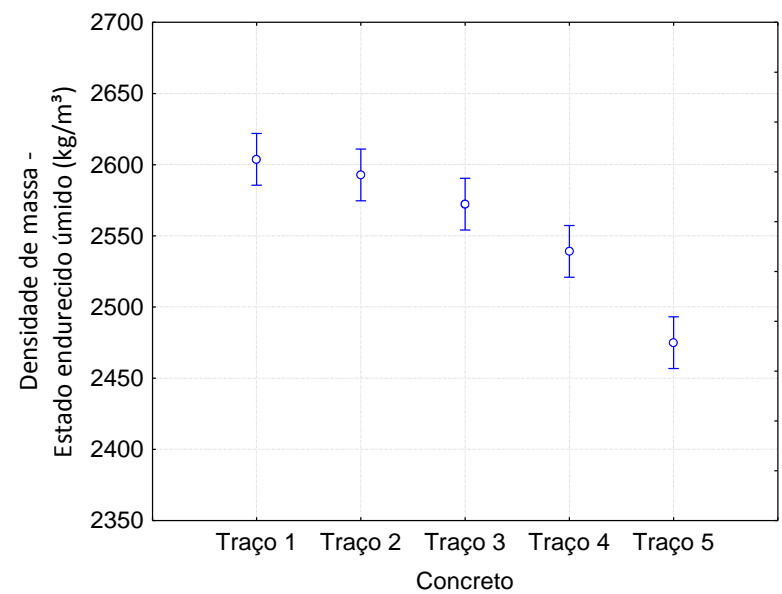

(a)

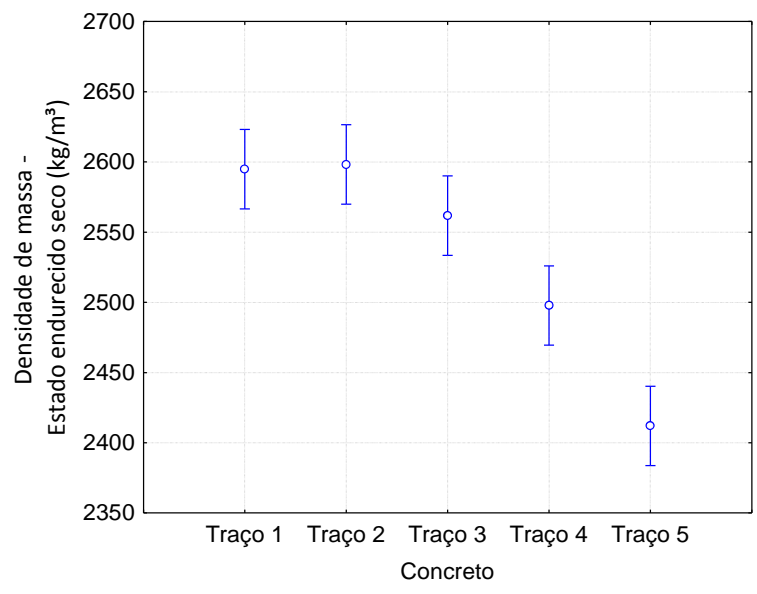

(b)

Figura 10: a) Densidade de massa no estado endurecido e úmido em função do traço dos concretos, LS means; b) Densidade de massa no estado endurecido e seco em função do traço dos concretos, LS means.

\subsection{Molhabilidade Superficial}

Exemplos de imagens obtidas no ensaio de molhabilidade superficial dos concretos são apresentados na Figura 11, juntamente com sua respectiva resistência potencial. Observando-se a Figura 11a, verifica-se que o concreto com o traço 1, de maior resistência potencial, tende a ser mais hidrofóbico, por apresentar um elevado ângulo de contato entre o substrato e a gota d'água. Por outro lado, o traço 5 (Figura 11e), de menor resistência potencial, apresenta um menor ângulo de contato entre o substrato e a gota d'água, indicando que esse tende a ser mais hidrofílico, ou seja, tende a apresentar um melhor espalhamento na base. Observa-se 
também que os demais traços apresentam comportamentos intermediários a estes dois exemplos.

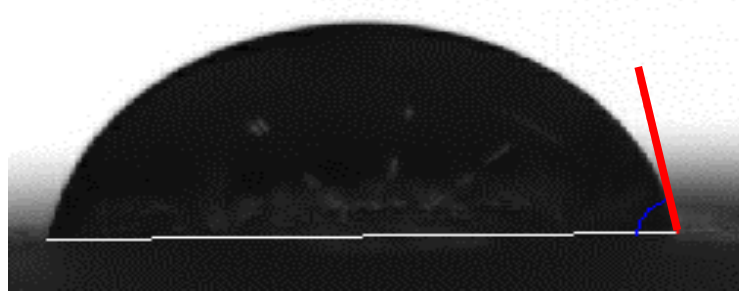

(a)

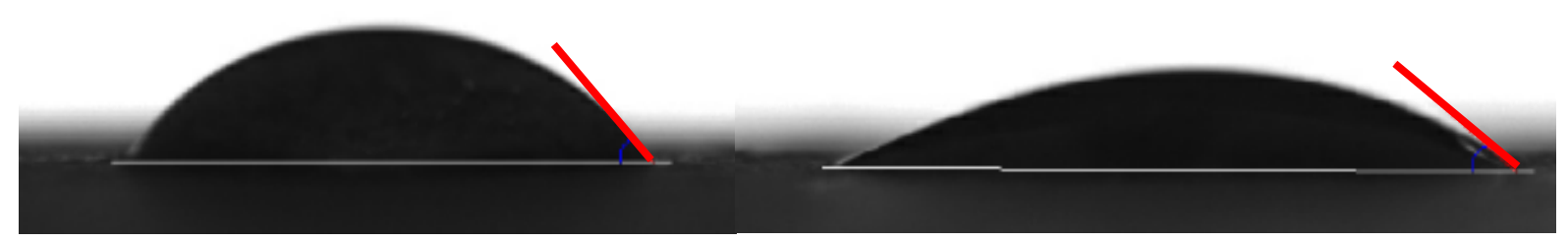

(c)

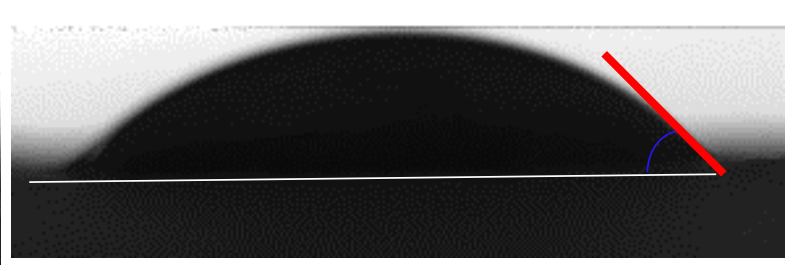

(b)

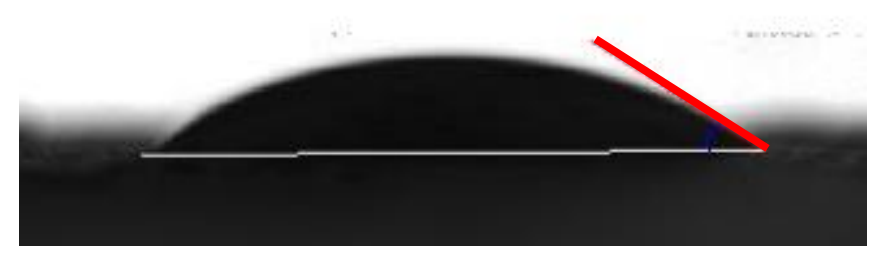

(e)

Figura 11: Ângulo de contato de uma gota na superfície do concreto com a) traço $1-118,60 \mathrm{MPa}, 58,7^{\circ}$; b) traço 2 108,26 MPa, 47,6 $6^{\circ}$ c) traço $3-102,89 \mathrm{MPa}, 49,8^{\circ}$; d) traço $4-91,10 \mathrm{MPa}, 31^{\circ}$; e) traço $5-48,48 \mathrm{MPa}, 31,1^{\circ}$.

A figura 12 apresenta os resultados do ângulo de contato para cada um dos diferentes traços de concreto estudados. Conforme o teste comparativo de médias de Duncan (Tabela 5), identificou-se que os traços 2 e 3, bem como os traços 4 e 5, apresentaram resultados semelhantes estatisticamente. Porém, no contexto geral, evidencia-se uma redução do ângulo de contato com a modificação do traço (redução do teor de aglomerantes e aumento da relação água/aglomerante). 


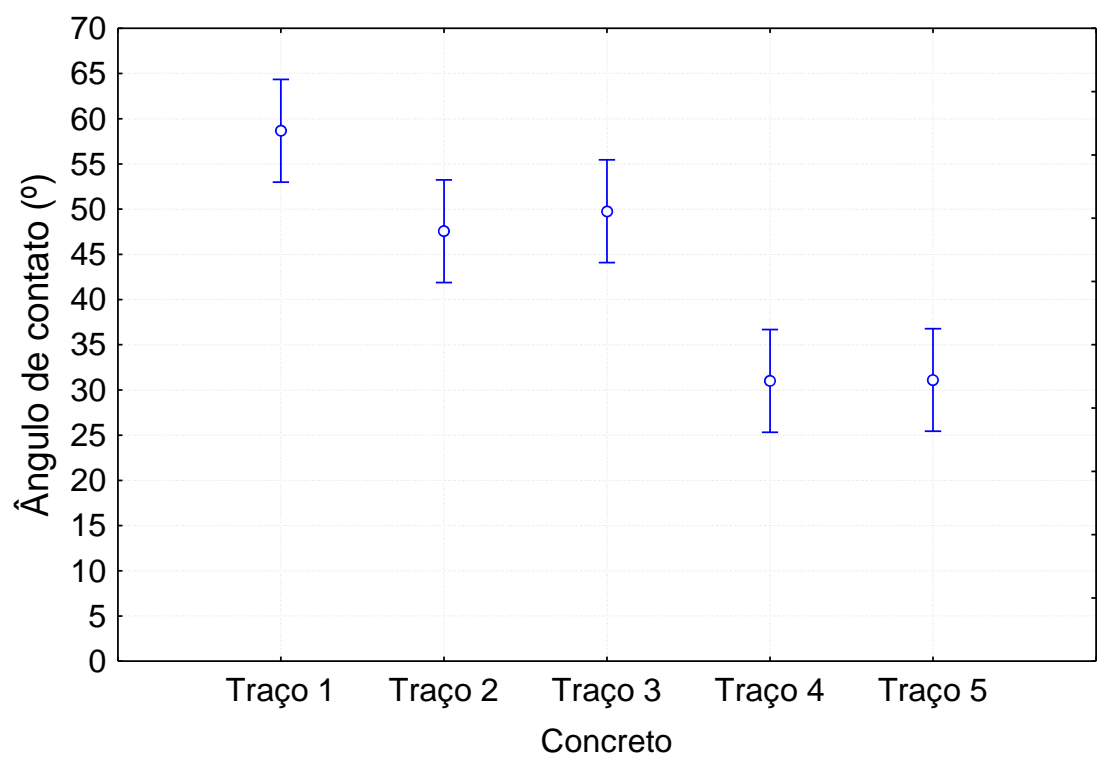

Figura 12: Ângulo de contato em função dos traços dos concretos, LS means.

Tabela 5: Análise de Duncan entre o ângulo de contato da superfície dos diferentes traços de concreto; há diferença significativa entre dois traços comparados quanto ao fator analisado quando o valor é menor de 0,05 .

\begin{tabular}{l|l|l|l|l|l}
\hline & TRAÇO 1 & TRAÇO 2 & TRAÇO 3 & TRAÇO 4 & TRAÇO 5 \\
\hline TRAÇO 1 & & 0,010657 & 0,030995 & 0,000031 & 0,000054 \\
\hline TRAÇO 2 & 0,010657 & & 0,579136 & 0,000280 & 0,000281 \\
\hline TRAÇO 3 & 0,030995 & 0,579136 & & 0,000101 & 0,000101 \\
\hline TRAÇO 4 & 0,000031 & 0,000280 & 0,000101 & & 0,977930 \\
\hline TRAÇO 5 & 0,000054 & 0,000281 & 0,000101 & 0,977930 & \\
\hline
\end{tabular}

Os resultados estão coerentes com trabalhos anteriores. Em concreto com resistência à compressão média de 36,63 MPa, moldado em fôrma de compensado naval, o ângulo de contato médio obtido na superfície foi de $28^{\circ}$ [29]. Em análise semelhante, para um concreto com proporcionamento 1:3 (aglomerante:agregados) e resistência à compressão média de $43,5 \mathrm{MPa}$, o ângulo de contato na superfície em contato com a fôrma de compensado naval resultou em um valor médio pouco acima de $50^{\circ}$ [30]. Para faixas de concreto com resistência à compressão mais elevada, não foram verificados estudos relacionados com a avaliação da molhabilidade superficial.

Na Figura 13, fez-se uma comparação entre a resistência à compressão dos concretos e o ângulo de contato, e outra, entre a absorção de água por capilaridade em 72 horas com o ângulo de contato. Observa-se, para cada traço, uma proporcionalidade do comportamento entre os dois fatores, no primeiro caso, e uma inversão deste, no segundo caso. 


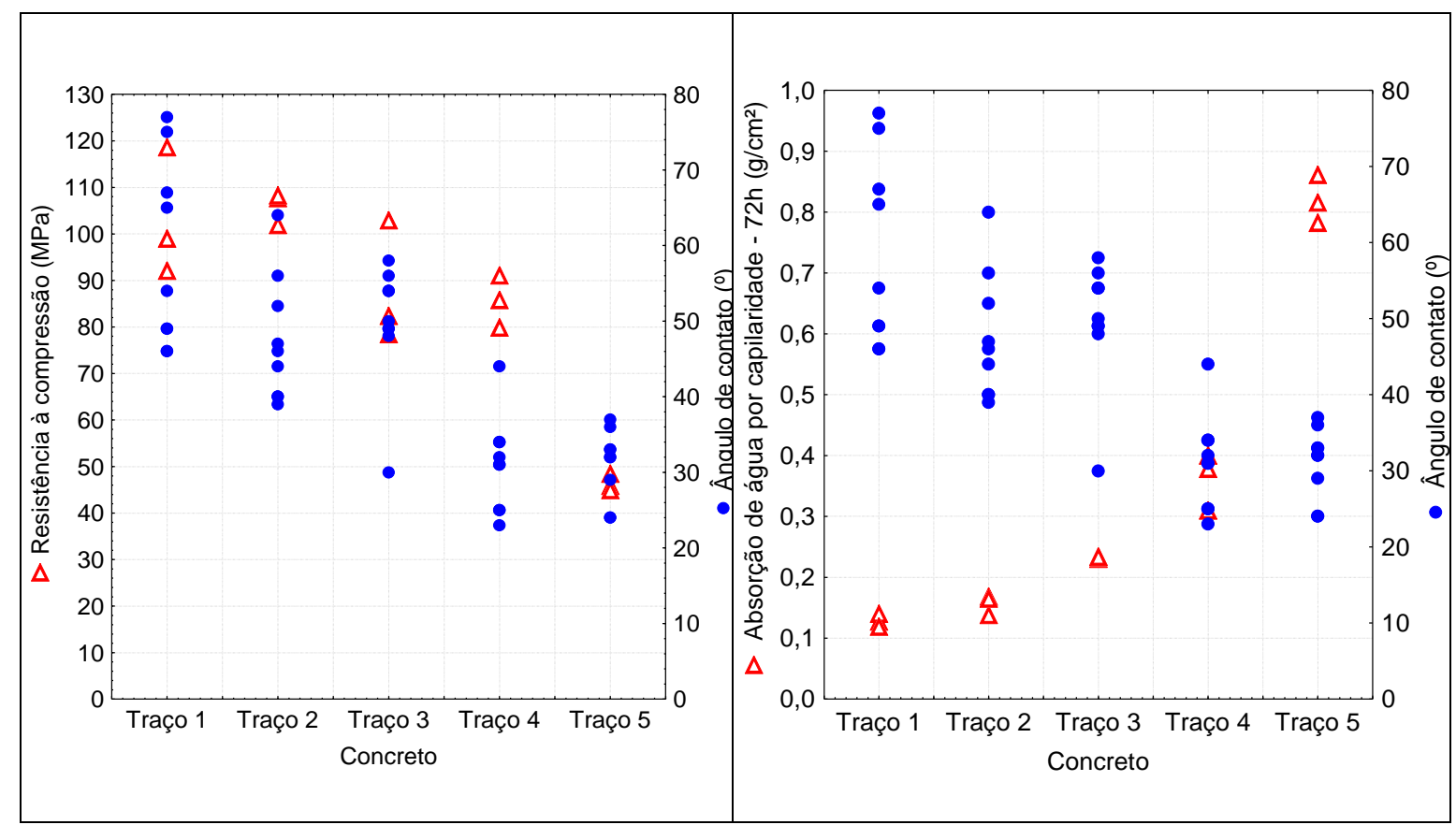

(a)

(b)

Figura 13: a) Resistência à compressão e ângulo de contato, em função dos traços dos concretos; b) Absorção de água por capilaridade em 72 horas e ângulo de contato, em função dos traços dos concretos.

\section{CONCLUSÕES}

Em vista do trabalho realizado, pôde-se concluir que existe uma tendência de que a superfície de concretos com maiores resistências à compressão e menores absorções de água por capilaridade apresentarem um maior ângulo de contato com uma gota de água. Ou seja, estes concretos apresentam uma maior hidrofobicidade e menor molhabilidade superficial. À medida que a resistência à compressão diminui e a absorção capilar aumenta, a molhabilidade tende a aumentar.

Os resultados aqui obtidos com relação à molhabilidade da superfície podem ser correlacionados com o espalhamento das argamassas de revestimento. Um concreto de alta resistência, com uma superfície que tende a ser hidrofóbica e de menor molhabilidade, pode vir a proporcionar uma menor adesão e aderência do revestimento, o que pode vir a comprometer suas funções. A análise mostra-se compatível com o que ocorre na prática, nos canteiros de obra.

\section{AGRADECIMENTOS}

À Capes e ao CNPq, pela concessão das bolsas de estudo. Ao Laboratório de Cerâmicos da UFRGS (LACER/UFRGS), por ter disponibilizado o equipamento de captura de gota séssil. Ao Laboratório de Materiais e Tecnologia do Ambiente Construído da UFRGS (LAMTAC-NORIE/UFRGS), no qual foi realizada a moldagem dos concretos e demais ensaios.

\section{BIBLIOGRAFIA}

[1] MORENO JÚNIOR, R., SELMO, S. M., Aderência de Argamassas de Reparo de Estruturas de Concreto, Boletim Técnico da Escola Politécnica da USP, São Paulo, 2007.

[2] ASSOCIAÇÃO BRASILEIRA DE NORMAS TÉCNICAS, NBR 13528: revestimento de paredes de argamassas inorgânicas — Determinação da resistência de aderência à tração, Rio de Janeiro, 2010.

[3] NEPOMUCENO, A. A., "Mecanismo de transporte de fluídos no concreto”, In: Isaia, G. C. (ed), Concreto ensino, pesquisa e realizações, capítulo 26, São Paulo, IBRACON, 2005.

[4] MEHTA, P. K., MONTEIRO, P. J. M, Concreto: microestrutura, propriedades e materiais, $3^{\mathrm{a} e d . . ~ S a ̃ o ~}$ Paulo, IBRACON, 2008. 
[5] CASCUDO, O., Controle da corrosão de armaduras em concreto: inspeção e técnicas eletroquímicas.

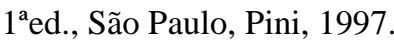

[6] PRETTO, M. E. J., "Influência da rugosidade gerada pelo tratamento superficial do substrato de concreto na aderência do revestimento em argamassa", Dissertação de M.Sc, PPGEC/UFRGS, Porto Alegre, RS, Brasil, 2007.

[7] WENZEL, R. N., "Resistance of Solid Surfaces to Wetting by Water", Industrial and Engineering Chemistry, v. 28, n. 8, pp. 988-994, Ago. 1936.

[8] CASSIE, A. B. D., BAXTER, S., "Wettability of porous surfaces", Transactions of the Faraday Society, v. 40, pp. 546-551, Jun. 1944.

[9] LATTHE, S. S., GURAV, A. B., MARUTI, C. S., et al., "Recent process in preparation of superhydrophobic surfaces: a review", Journal of Surfaces Engenneered Materials and Advanced Technology, v. 2, pp. 76-94, Jan. 2012.

[10] VIECHINESKI, F. N., "Preparação e caracterização de filme transparente polimérico hidrofóbico para aplicação em superfícies de vidro", Dissertação de M.Sc., PPGEP/UTFPR, Ponta Grossa, PR, Brasil, 2015.

[11] NUNES, B. M. F., "Funcionalização de superfícies de silício por radiação laser e implantação iônica: estudo da molhabilidade", Dissertação de M.Sc., NEMat/IST, Lisboa, Portugal, 2008.

[12] COURARD, L., LUCQUIAUD, V., GÉRARD, O., et al., "Evaluation of the durability of hydrophobic treatments on concrete architectural heritage", In: Hydrophobe VII:7th International Conference on Water Repellent Treatment and Protective Surface Technology for Building Materials, pp. 29-38, Lisboa, Set. 2014.

[13] KINDLEIN JUNIOR, W., HUBNER, A. B., STOLZ, C. M., et al., Biônica e Design de Superfície: Influência da textura na molhabilidade de superfícies naturais e artificiais, In: $10^{\circ}$ Congresso Brasileiro de Pesquisa e Desenvolvimento em Design, pp. 5529-5541, São Luiz, Out. 2012.

[14] DAPPER, S. T. H., "Desenvolvimento de textura bioinspirada no líquen Parmotrema Praesorediosum visando a adesão da argamassa de revestimento em painéis de concreto", Dissertação (Mestrado em Engenharia Civil) - Programa de Pós-Graduação em Design, UFRGS, Porto Alegre, RS, Brasil, 2013.

[15] STOLZ, C. M., MASUERO, A. B., "Analysis of main parameters affecting substrate/mortar contact area through tridimensional laser scanner", Journal of Colloid and Interface Science, v. 455, pp. 16-23, Out. 2015.

[16] ASSOCIAÇÃO BRASILEIRA DE NORMAS TÉCNICAS, NBR 15575-1: edificações habitacionais desempenho, Parte 1:requisitos gerais, Rio de Janeiro, 2013.

[17] COSTA, E. B. C., "Análise de parâmetros influentes na aderência de matrizes cimentícias", Tese (Doutorado em Engenharia) - Programa de Pós-Graduação em Engenharia Civil, EPUSP, São Paulo, SP, Brasil, 2014.

[18] ASSOCIAÇÃO BRASILEIRA DE NORMAS TÉCNICAS, NBR 9779: Argamassa e concreto endurecidos - Determinação da absorção de água por capilaridade, Rio de Janeiro, 2012.

[19] PETRY, S. B., "Estudo da permeabilidade à água na camada de cobrimento de protótipos de concretos com alto teor de cinza volante", Dissertação (Mestrado em Engenharia Civil), UFSM, Santa Maria, RS, Brasil, 2004.

[20] ISAIA, G. C. "Avanços e perspectivas sobre a durabilidade do concreto com altas adições minerais", In: II Seminário Internacional sobre Durabilidade das Estruturas de Concreto. Goiânia, 2002.

[21] CARASEK, H., "Aderência de argamassas à base de cimento Portland a substratos porosos: avaliação dos fatores intervenientes e contribuição ao estudo do mecanismo da ligação", Tese (Doutorado em Engenharia de Construção Civil e Urbana), Escola Politécnica da USP, São Paulo, SP, Brasil, 1996.

[22] SCARTEZINI, L.M.B., "Influência do tipo de preparo do substrato na aderência dos revestimentos de argamassa: estudo da evolução ao longo do tempo, influência da cura e avaliação da perda de água da argamassa fresca”, Dissertação (Mestrado em Engenharia Civil), UFG, Goiás, GO, Brasil.

[23] ROHDEN, A. B., "Contribuição aos métodos de dosagem de concreto de alta resistência a partir do entendimento da influência dos agregados na mistura", Tese (Doutorado em Engenharia), UFRGS, Porto Alegre, RS, 2015.

[24] ASSOCIAÇÃO BRASILEIRA DE NORMAS TÉCNICAS, NBR 7212: Execução de concreto dosado em central - Procedimento, Rio de Janeiro, 2012.

[25] ASSOCIAÇÃO BRASILEIRA DE NORMAS TÉCNICAS, NBR 5739: Concreto - Ensaio de compressão de corpos-de-prova cilíndricos, Rio de Janeiro, 2007. 
[26] VENQUIARUTO, S., OSSORIO, A., ZANINI, C., et al., “Aproveitamento de Resíduos de Ágata Reciclada em Materiais Cimentícios Sustentáveis", In: Hartmann, L. A; Silva, J. T. da; Donato, M (Orgs), Tecnologia e Inovação em Gemas, Joias e Mineração, capítulo 13, pp. 99-106, Porto Alegre, Brasil, IGEO/UFRGS, 2014.

[27] GIORDANI, C., "Viabilidade técnica do uso de resíduos do beneficiamento de arenito como substituição do agregado miúdo em argamassas", Trabalho de Diplomação (Graduação em Engenharia Civil), UFRGS, Porto Alegre, RS, Brasil, 2014.

[28] PETRY, N. dos S., "Uso de resíduos de ágata como agregado em argamassas de cimento Portland branco”, Dissertação (Mestrado em Engenharia Civil), UFRGS, Porto Alegre, RS, Brasil,2015.

[29] DAPPER, S. T. H., MASUERO, A. B., KINDLEIN JUNIOR, W., "Influência do material da fôrma na molhabilidade da superfície do concreto", In: Simpósio Brasileiro de Tecnologia das Argamassas, pp. 7-10, Porto Alegre, Abr. 2015

[30] DAPPER, S. T. H., MASUERO, A. B., KINDLEIN JUNIOR, W. "Estudo sobre a relação da molhabilidade e absorção capilar de superfícies de concretos quando moldados sobre diferentes materiais de fôrmas", In: Simpósio Brasileiro de Tecnologia das Argamassas, pp. 5-9, São Paulo, Ago. 2017.

\section{ORCID}

Angela Masuero

Caroline Giordani

Emili Cappelari

Silvia Trein Heimfarth Dapper https://orcid.org/0000-0001-9117-8346

https://orcid.org/0000-0003-0208-6592

https://orcid.org/0000-0002-4035-3551

https://orcid.org/0000-0001-6791-7364
ERRATA
Onde se lia:
Caroline Giodani $^{2}$
Leia-se:
Caroline Giordani ${ }^{2}$
Revista Matéria (2020) 25 (1) e-12375 